RAZGLEDI

\title{
MLADINSKI TURIZEM IN POTOVALNE NAVADE ŠTUDENTOV - PRIMER UNIVERZE NA PRIMORSKEM
}

\author{
AVTORJA \\ Marko Pavlič \\ Streliška pot 60, SI - 5000 Nova Gorica, Slovenija \\ marko_pavlic@hotmail.com
}

dr. Miha Koderman

Univerza na Primorskem, Fakulteta za humanistične študije, Titov trg 5, SI - 6000 Koper, Slovenija

miha.koderman@fhs.upr.si

DOI: $10.3986 / G V 86105$

UDK: 338.48-2-053.6(497.472Koper)

COBISS: 1.01

\section{IZVLEČEK}

\section{Mladinski turizem in potovalne navade študentov - primer Univerze na Primorskem}

Prispevek obravnava problematiko mladinskega turizma, skaterim je po ocenah ekonomistov letno povezana petina vseh opravljenih turističnih potovanj na globalni ravni. V prvem delu članka je opredeljen segment mladinskega turizma, nato pa je podan pregled poglavitnih študij, ki obravnavajo turistično mobilnost slovenskih študentov. Slednjo sta avtorja preučevala na primeru študentov Univerze na Primorskem. Predstavljeni izsledki se nanašajo na potovalne navade študentov, med katerimi so izpostavljena zlasti območja turističnega obiska, trajanje in pogostost potovanj ter organizacijski in finančni vidiki potovanja.

\section{KLJUČNE BESEDE}

mladinski turizem, mladi, študenti, potovalne navade, Univerza na Primorskem

\section{ABSTRACT}

\section{Youth tourism and travel habits of students - the case of the University of Primorska}

The article deals with the issue of youth tourism, a phenomenon which according to the economists yearly generates one fifth of all tourism flows globally. The authors first present the concepts and scope of youth tourism and provide an overview of major studies addressing the tourist mobility of the Slovenian student population. The second part of the article summarizes the main findings of empirical research, conducted among the students of University of Primorska. The presented results refer to the travel habits of students, among which the main areas of tourist visits, duration and frequency of travel as well as organizational and financial aspects of the travel are exposed.

\section{KEY WORDS}

youth tourism, young people, students, travel habits, University of Primorska

Uredništvo je prispevek prejelo 3. aprila 2014. 


\section{Uvod}

Turizem je večplastna dejavnost, povezana $\mathrm{z}$ različnimi družbenimi skupinami, ki imajo vsaka svoje specifične motivacijske dejavnike, zaradi katerih se posamezniki odločajo za turistična potovanja. Turistična tipologija deli turistične dejavnosti na prostočasne in poslovne (Swarbrooke in Horner 1999), med bolj izpopolnjenimi delitvami pa velja omeniti Tezaver turizma in prostočasnih dejavnosti Svetovne turistične organizacije (UNWTO 2001), ki s podrobnim vsebinskim razločevanjem opredeljuje kar 24 temeljnih turističnih področij. Slednje bi lahko razdelili tudi glede na socialno in starostno strukturo udeležencev (mladinski turizem, družinski turizem in turizem za starejše), o čemer med drugim priča raznolika »nišna « turistična ponudba, ki se je za vsakega izmed omenjenih segmentov že oblikovala na turističnih trgih (tudi na slovenskem).

Mladinski turizem se je - vsaj v takšni obliki, kot ga poznamo danes - pričel intenzivneje razvijati vzporedno $\mathrm{z}$ rastjo turistične dejavnosti, ki se je razširila v letih po 2. svetovni vojni. Mladi so bili v tem obdobju del velikih družbenih sprememb in so se od ostalih družbenih skupin razločevali po alternativnem, drugačnem načinu življenja, kar se je izrazilo tudi pri načinu preživljanja prostega časa. Potovanja so skupaj z ostalimi rekreativnimi dejavnostmi postala cenovno dostopnejša, zaradi česar so lahko tudi mladi sledili toku družbe, ki se je v tem času vse bolj turistično udejstvovala (Mihalič 2008, 19).

V ekonomskem smislu dosega mladinski turizem pomembne učinke. Raziskovalci svetovne turistične organizacije ocenjujejo, da so potovanja mladih med letoma 2002 in 2007 zajemala prek 160 milijonov mednarodnih prihodov turistov letno (oziroma prek $20 \%$ vseh), s čimer je bilo ustvarjenih okoli 136 milijard ameriških dolarjev prometa (oziroma $18 \%$ vsega turističnega prometa letno). Mladinski turizem naj bi v obravnavanih letih izkazoval od 3 do $5 \%$ letno rast v obsegu potovanj ter $8 \%$ letno rast prihodkov (UNWTO 2008, xi). Hkrati študija izpostavlja, da imajo turistična potovanja mladih zaradi specifičnih značilnosti te populacije daljšo povprečno dobo bivanja ter tako izkazujejo tudi višjo povprečno potrošnjo od preostalih turistov. Povprečni turist je leta 2010 na potovanjih porabil 1450 ameriških dolarjev, »mladi« turist pa kar 2600 ameriških dolarjev (WYSE ... 2013, 6-8).

Kot ugotavlja Pogačnik $(2008,185)$, so v socialnem in prostorskem smislu za mladinski turizem značilni velika stopnja mobilnosti, nezahtevnost pri logistiki (prenočiščih, prehrani in transportu), raznovrstne dejavnosti pri športu, uživanje kulturnih, zabavnih, izobraževalnih in drugih dobrin. Poglavitni cilji mladinskega turizma so enaki kot cilji preostalega, zlasti potovalnega turizma. Mladi so poleg tega po oceni Pogačnika (2008) odlični ambasadorji spoznavanja določene države oziroma kraja in ustvarjanja njunega slovesa, saj njihove informacije hitro dosežejo drugo mladino, starše in medije. Mladi turisti lahko popestrijo turistični utrip posameznega kraja in mu dajo mednarodni pečat, čar mladostne radoživosti in svetovljanstva, kar pozitivno vpliva tudi na druge populacije turistov.

Izbrani statistični pokazatelji turizma mladih v Sloveniji kažejo, da mladi opravijo med 20 do $30 \%$ vseh počitniških potovanj (to je zasebnih potovanj z najmanj štirimi nočitvami) (Commission ... 2009, 83). Leta 2011 se je po podatkih vsakoletne raziskave slovenskega statističnega urada (Turistična potovanja domačega prebivalstva) vsaj enega turističnega potovanja udeležilo $80,6 \%$ prebivalcev Slovenije iz starostne skupine 15-24 let, sledila je srednja starostna skupina 25-44 let $(77,1 \%)$, najmanjši delež pa je bil evidentiran v najstarejši starostni skupini nad 64 let (27,9\%). Trend nakazuje rahlo rast turistične mobilnosti mladih v zadnjih desetih letih. Podobno sliko kaže primerjava nekaterih socialnih skupin: leta 2011 je potovalo $84,8 \%$ populacije dijakov in študentov, 73,4\% populacije zaposlenih in samozaposlenih ter le 35,3\% upokojencev (SURS 2012a, 2).

Večino daljših potovanj so mladi v letu 2011 opravili v poletnih mesecih (kar $68,6 \% \mathrm{v}$ obdobju od julija do septembra). Povprečna dnevna poraba na turistični destinaciji je bila med mladimi najvišja (48 evrov), a so mladi hkrati za posamezno potovanje namenili manj časa. Na turističnih potovanjih po Sloveniji so v povprečju opravili 2,6 nočitve, v tujini pa 5,4 nočitve. V večji meri kot sicer so mladi kot glavni motiv za potovanje navedli sprostitev, počitek in zabavo, $v$ manjši meri kot ostali pa željo po rekreaciji ter ogledu znamenitosti (SURS 2012a, 3-21). 


\section{Opredelitev ključnih pojmov in metodološka pojasnila}

\subsection{Mladinski in študentski turizem}

Za podrobnejše in celovitejše razumevanje obravnavane tematike podajamo v nadaljevanju opredelitve nekaterih pojmov, ki zaznamujejo mladinski oziroma študentski turizem. Tako lahko najprej ugotovimo, da je pojem »mladina « oziroma »mladi« precej širok in nedefiniran. Celo skupna raziskava Svetovne mladinske, študentske in izobraževalne potovalne organizacije (World Youth Student and Educational Travel Confederation) ter Svetovne turistične organizacije iz leta 2005 je pokazala, da posamezne nacionalne turistične organizacije postavljajo različne objektivne kriterije pri definiranju pojma mladih in mladinskega turizma. Študija ob tem kaže, da se v mnogih primerih v praksi starostna omejitev uporablja le kot dopolnilni kriterij. Obenem Svetovna turistična organizacija predlaga tudi (svojo) definicijo mladinskega turizma: "Mladinska potovanja vključujejo vsa samostojna potovanja s strani populacije, stare med 16 in 29 let, ki niso daljša od 1 leta in so delno ali popolnoma motivirana $v$ želji po spoznavanju drugih kultur, nabiranju novih življenjskih izkušenj in/ali v formalnem in neformalnem spoznavanju priložnosti zunaj domačega okolja (UNWTO 2008, 1). V primeru mladinskega turizma torej ta organizacija mlade prepoznava kot generacijo med 16. in 29. letom starosti, podobno kot številni nacionalni statistični uradi, vključno z evropskim in slovenskim statističnim uradom. Vendar je ob tem treba upoštevati dejstvo, da se predvsem v razvitih državah ob vse daljšem in zahtevnejšem izobraževalnem procesu, visoki stopnji brezposelnosti med mladimi diplomanti in naraščajočih stroških bivanja, mladi vse kasneje osamosvojijo, zato se v nekaterih primerih kot starostni kriterij za mlado prebivalstvo postavlja meja 35 let.

V Sloveniji je ob koncu leta 2013 starostna skupina prebivalstva med 16. in 29. letom starosti obsegala 331.292 oseb (SURS 2014a). Mednje sodi tudi velika večina od 90.573 študentov, ki so bili v študijskem letu 2013/2014 vpisani na višje strokovne šole, univerze in samostojne visokošolske zavode (prebivalci Slovenije, ki so starejši od 29 let, med študenti predstavljajo le manjši, zanemarljiv delež) (SURS 2014b). Za študenta se šteje vsaka oseba, ki se je vpisala in se izobražuje na višješolskem ali visokošolskem zavodu (Zakon ... 1993). Študenti so torej posebna socialna struktura znotraj skupine mladih in študentski turizem je (tudi glede na ključne značilnosti) pomemben del mladinskega turizma, ki ga izpostavljamo v nadaljevanju.

Svetovna turistična organizacija (Richards 2005, 101-103) na področju mladinskega turizma prepoznava več podzvrsti, prek katerih se ta turizem največkrat izraža:

- študentski turizem, ki je precej povezan s študijskim procesom, vanj pa prištevamo tudi študijska potovanja in študijske izmenjave;

- nahrbtnikarski turizem navadno označuje daljše in samostojno potovanje; povezan je predvsem z rastjo mladinskega turizma v Avstraliji, Novi Zelandiji in na Tajskem;

- prostovoljski turizem in delovni počitniški programi (angl. Volunteer tourism and working holiday programmes), ki ga spodbujajo s posebnimi programi in agencijami za mlade prostovoljce;

- jezikovni turizem, ki predstavlja izkušnjo učenja tujega jezika, navadno v tuji državi; velja za neke vrste »kreativni turizem «, saj udeleženci potovanje izkoristijo kot možnost individualnega izpopolnjevanja znanja;

- turizem kulturnih izmenjav, ki predstavlja nekoliko širši koncept kot jezikovni turizem in je povezan predvsem z željo izobraževanja tujih državljanov o lastni kulturi oziroma izobraževanja lastnih državljanov o tujih kulturah.

\subsection{Metodologija}

V raziskavo o potovalnih navadah študentov Univerze na Primorskem smo skušali zajeti reprezentativen vzorec celotne populacije, zato smo uporabili metodo kvotnega vzorčenja (angl. quota sampling). Kvotno vzorčenje se nasploh uporablja v trženjskem raziskovanju in raziskavah javnega mnenja, denimo 
v javnomnenjskih anketah o političnih temah. Namen kvotnega vzorčenja je pridobiti končni vzorec, ki bo reprezentativno odražal razmerja v populaciji na podlagi različnih kategorij, kot na primer spola, etnične pripadnosti, starostnih skupin, regije/kraja bivanja. Vzorčenje po tej metodi ne poteka naključno, temveč je končna selekcija vzorca prepuščena izvajalcu. Podatke o razmerjih v širši opazovani populaciji lahko izvajalec pridobi od različnih institucij, ki so zadolžene za zbiranje informacij (Bryman 2012, 203; Neuman 2006, 346-353), v našem primeru je bil to Sektor za izobraževanje Univerze na Primorskem, ki razpolaga s podatki o vpisu študentov na posamezne fakultete in programe.

Za potrebe raziskave smo sestavili spletni anketni vprašalnik (na spletnem portalu https://www.1ka.si/). Raziskava je bila na spletu aktivna med 20. majem in 9. septembrom 2013, v omenjenem obdobju pa smo uspeli pridobiti 217 zaključenih anketnih vprašalnikov. Z metodo kvotnega vzorčenja smo omogočili uravnoteženo zastopanost študentov po posameznih fakultetah Univerze na Primorskem, zato smo v prvi fazi obravnave pridobljenih podatkov izločili presežek anketnih vprašalnikov tako, da je bil delež prejetih odgovorov iz posameznih fakultet primerljiv z deležem nanjo vpisanih študentov (preglednica 1). Tako je bilo v drugo fazo obravnave uvrščenih skupno 150 anketnih vprašalnikov, kar predstavlja ob dejstvu, da je bilo v študijskem letu 2012/2013 na vseh študijskih programih Univerze na Primorskem vpisanih 6606 študentov, skupno 2,27\% celotne populacije vpisanih študentov.

Preglednica 1: Število in delež vpisanih študentov na študijskih programih Univerze na Primorskem po posameznih fakultetah $v$ študijskem letu 2012/2013 (Sektor... 2013).

\begin{tabular}{lccc}
\hline fakulteta & $\begin{array}{c}\text { število vpisanih } \\
\text { študentov }\end{array}$ & $\begin{array}{c}\text { delež vpisanih } \\
\text { studentov }\end{array}$ & $\begin{array}{c}\text { število vprašalnikov, } \\
\text { ki so bili vključeni } \\
\text { v analizo }\end{array}$ \\
\hline $\begin{array}{l}\text { Fakulteta za matematiko, naravoslovje } \\
\text { in informacijske tehnologije }\end{array}$ & 699 & 10,6 & 16 \\
Fakulteta za humanistične študije & 621 & 9,4 & 14 \\
Fakulteta za management & 1734 & 26,2 & 39 \\
Fakulteta za turistične študije - Turistica & 1097 & 16,6 & 25 \\
Fakulteta za vede o zdravju & 836 & 12,7 & 19 \\
Pedagoška fakulteta & 1619 & 24,5 & 37 \\
SKUPAJ & 6606 & 100,0 & 150 \\
\hline
\end{tabular}

V osrednjem delu prispevka tako predstavljamo rezultate univariatne analize, ki se nanašajo na skupno anketirano populacijo $(\mathrm{N}=150)$.

\section{Slovenski mladinski in študentski turizem v literaturi}

Mihaličeva $(2008,16-19)$ korenine sodobnega mladinskega turizma postavlja v obdobje po drugi svetovni vojni, prostočasne dejavnosti mladih pa so se še dodatno okrepile v 70. letih 20 . stoletja, ko so začeli "Zavračati « klasični, masovni turizem in odkrivali druge, manj komercialne načine potovanj. Mladinski turizem je veljal za alternativnega, hkrati pa mladi niso veljali za klasične turiste, temveč prej za popotnike.

Glede na obseg in pomembnost v globalnem merilu je področje mladinskega in študentskega turizma v slovenski strokovni literaturi relativno zapostavljeno. V nadaljevanju predstavljamo izsledke nekaterih sorodnih raziskav, ki so bile opravljene bodisi v obliki samostojnih raziskav, bodisi so nastale v okviru diplomskih del in se dotikajo potovalnih navad študentov oziroma mladih v Sloveniji. Med prvimi lahko omenimo Antona Gosarja (1989), ki je preučeval potovanja študentov geografije. Avtor na podlagi 142 pridobljenih mnenj podaja spoznanja o preživljanju poletnih počitnic, obisku naravnih in kulturnih 
znamenitosti v Sloveniji ter rekreaciji v izletniškem območju domačega kraja. Med anketiranci ( $\mathrm{z}$ večinskim, 88,1 \% deležem oseb, starih od 18 do 23 let) je po priljubljenosti izstopalo območje zahodne Istre (Poreč in okoliška turistična naselja), kjer je počitnice v obravnavanih štirih letih (1985-1989) preživelo 29,5 \% študentov geografije. Sledili so kraji v slovenskem Primorju (zlasti Portorož), Kvarnerski otoki (Lošinj) in območja v slovenskih Alpah.

Na leto 1998 se nanaša delo Nataše Gostiša (2000), ki je analizirala družbenogeografske značilnosti turističnih potovanj rednih študentov Univerze v Ljubljani. V vzorec, ki ga avtorica podrobneje ne razčlenjuje po posameznih fakultetah, je vključila 210 študentov, kar je takrat predstavljalo $0,65 \%$ celotne populacije. V delu med drugim ugotavlja, da so študentje družboslovnih smeri potovali pogosteje $\mathrm{v}$ primerjavi z ostalimi, glede na letnik študija pa so močno izstopali zlasti absolventi in tudi študentje prvih letnikov. Med izpostavljenimi destinacijami so študentje najpogosteje navajali kraje in območja po Sloveniji, kjer je bila zabeležena tretjina vseh potovanj, z $29 \%$ deležem je sledila Hrvaška, manjši odstotki navedb pa so se nanašali tudi na kraje v Grčiji, Avstriji in Italiji. Na potovanja so v večini (54 \%) odhajali $\mathrm{z}$ avtomobilom (kot sopotniki oziroma $\mathrm{z}$ lastnim ali družinskim vozilom).

Tudi Vesna Pehan (2007) je potovalne navade študentov preučevala na populaciji Univerze v Ljubljani (342 študentov). Podobno kot Gosar in Gostiša je tudi ona med študentsko populacijo zaznala izrazito vlogo individualnega načrtovanja in organiziranja potovanj. Edine storitve, ki jih študentje pred potovanjem urejajo prek turističnih agencij, so se nanašale na rezervacijo nastanitev, prevoz in zavarovanja. Turistično mobilnost študentov je označila kot visoko (le $8 \%$ sodelujočih v anketi je zatrdilo, da se v zadnjem letu niso odpravili na nobeno turistično potovanje), kot ključen razlog za potovanje pa so anketiranci navajali željo po sprostitvi, počitku in zabavi.

Visoko stopnjo turistične mobilnosti med študentsko populacijo je zaznal tudi Miha Koderman (2008), ki je leta 2008 opravil anketiranje med 322 dodiplomskimi študenti Univerze na Primorskem. Ti študentje so bili hkrati tudi močno mednarodno usmerjeni, saj jih $\mathrm{v}$ letu pred izvedbo anketiranja izven meja Slovenije ni potovalo le $5 \%$. Avtor med drugim izpostavlja glavne motive za potovanja ter ugotavlja, da je bila (kljub pregovorno skromnemu študentskemu "proračunu«) za večino študentov odločilni dejavnik za izbiro potovanja želena destinacija (68\%) in ne cena.

\section{Potovalne navade študentov Univerze na Primorskem}

V vzorec smo s tehniko kvotnega vzorčenja zajeli takšen delež anket, da je ustrezal deležu študentov po posameznih fakultetah. S tem smo želeli zagotoviti uravnoteženo zastopanost študentov posameznih smeri, saj denimo Gostiša $(2000,11)$ navaja, da študentje družboslovnih smeri potujejo pogosteje v primerjavi z naravoslovnimi, zato smo v tem pogledu skušali slediti strukturi populacije po fakultetah.

Med splošnimi značilnostmi anketirane populacije lahko izpostavimo prevladujoči delež žensk $(68,7$ \%) nad moškimi (31,3\%). Zaradi spoštovanja varstva osebnih podatkov nam ni uspelo pridobiti informacij o spolni strukturi študentov Univerze na Primorskem, ki bi omogočale primerjavo vzorca s celotno populacijo, lahko pa predpostavljamo, da je delež žensk na obravnavani univerzi višji od splošnega povprečja v državi, saj na splošno velja, da študentke prevladujejo na področju družboslovja, poslovnih ved, umetnosti, humanistike ter zdravstvenih ved (SURS 2012b), katerih študijski programi so številčnejše zastopani na Univerzi na Primorskem.

Med anketiranci je bilo največ ( $81 \%$ ) študentov 1 . bolonjske stopnje (dodiplomski študij), sledili so študenti 2 . bolonjske stopnje (18\%), študenti 3. bolonjske stopnje (doktorski študij) pa so v vzorcu predstavljali le $1 \%$. Anketni vzorec glede na ta razmerja bistveno ni odstopal od dejanske zastopanosti študentov Univerze na Primorskem na posameznih stopnjah študija.

Povprečna starost anketirancev je bila relativno visoka in je bila 24 let. Anketiranci so bili iz praktično vseh območij Slovenije, pogosteje pa so bili zastopani kraji iz zahodnega dela Slovenije (še zlasti iz Obalno-kraške in Goriške statistične regije). 


\subsection{Pogostost potovanj in območja turističnega obiska}

Analiza rezultatov izkazuje visoko mobilnost anketirancev. Skupno je le 5\% študentov navedlo, da v zadnjih dveh letih ni opravilo nobenega turističnega potovanja, kar je primerljivo s sorodnima raziskavama (Pehan 2007; Koderman 2008). Skoraj dve tretjini anketirancev je potovalo tako po Sloveniji, kot tudi v tujino.

Med tistimi, ki so potovali le na destinacije po Sloveniji, jih je največ (dobra polovica) obiskalo Gorenjsko statistično regijo, med pogosteje obiskanimi pa so bile še Obalno-kraška, Goriška in Pomurska statistična regija (slika 1). Anketirani študentje torej obiskujejo tiste regije v Sloveniji, ki tudi v splošnem beležijo visoke deleže turističnega obiska domačega prebivalstva.

Med tujimi državami, ki so jih anketirani študentje Univerze na Primorskem največkrat obiskali, prevladujejo sosednje države Hrvaška (68 \%), Italija (39\%) in Avstrija (27\%), ki so tudi tradicionalno med najbolj obiskanimi destinacijami turistov iz Slovenije (SURS 2012a, 1). Študenti v Evropi pogosteje obiskujejo še Češko, Francijo, Nemčijo, Španijo in Grčijo, izven Evrope pa so bili evidentirani (posamezni) obiski Egipta, Tajske, Združenih držav Amerike, Maroka, Malezije, Hondurasa in Gvatemale.

\subsection{Sezonskost, trajanje in organizacija turističnega potovanja}

Anketirani študentje Univerze na Primorskem so bili turistično najbolj mobilni v poletnih mesecih, podobno kot ostali mladi turisti v Sloveniji (SURS 2012a). Izraziti višek turističnih potovanj se pojavi v juliju in avgustu, $v$ nadpovprečni meri pa se potovanj udeležujejo od maja do septembra, kar je pričakovano glede na potek študijskih obveznosti. Povprečno potovanje je trajalo dobrih sedem dni (natančneje 7,17 dni), velika večina obravnavane populacije (91\%) pa je za potovanje v povprečju namenila do največ 10 dni. Najdaljše potovanje, ki so ga študentje Univerze na Primorskem izvedli v zadnjih dveh letih,

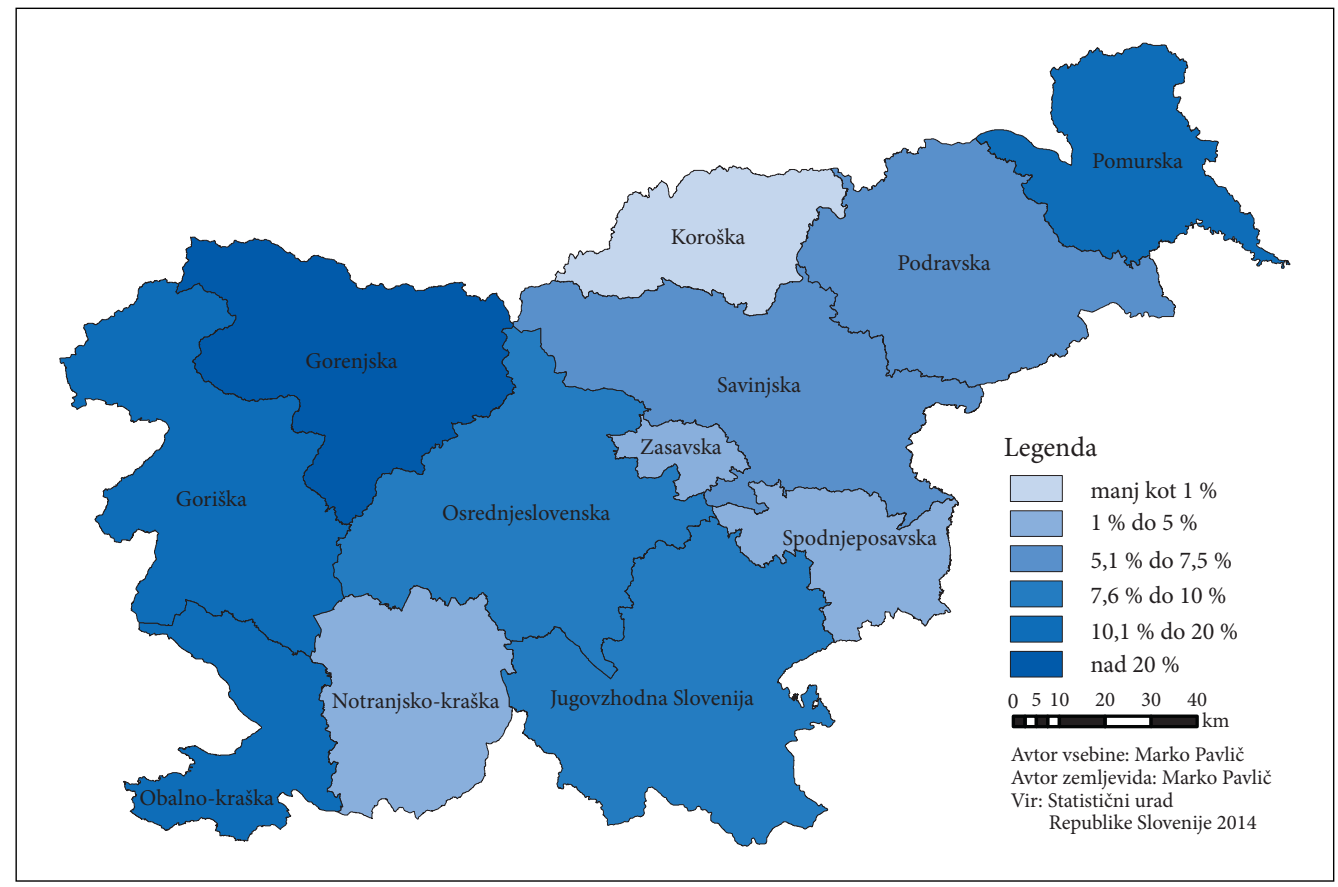

Slika 1: Delež turističnih obiskov študentov Univerze na Primorskem, ki so navedli destinacijo v Sloveniji po statističnih regijah $(N=90)$. 
je trajalo približno 17 dni. Kar $56 \%$ študentov med motivi za potovanje navaja željo po počitku in zabavi, sledi odkrivanje tujih krajev in kultur (31\%) ter obisk sorodnikov in prijateljev (7\%).

Eden izmed pomembnejših ciljev raziskave je bil ugotoviti poglavitne značilnosti in načine organizacije potovanj študentov. Izkazalo se je, da se kar tri četrtine anketiranih študentov na turistična potovanja odpravi s kolegi oziroma prijatelji, nekaj manj kot četrtina pa s sorodniki. Le zanemarljiv delež $(0,7 \%)$ potuje samih. Skoraj dve tretjini anketiranih študentov si potovanje običajno organizira samostojno, brez pomoči turistične agencije. Ostali v organizacijo potovanja tako ali drugače vključijo tudi potovalno agencijo: dobra petina uporablja njihove usluge le pri nekaterih storitvah (na primer nakup letalskih kart), $14 \%$ pa jih potuje izključno v organizaciji turistične agencije.

Internet je med anketiranimi študenti Univerze na Primorskem ključni vir informacij o potovanju, saj ga za pridobivanje potrebnih informacij uporablja velika večina $(94,9 \%)$ vprašanih. Približno polovica išče informacije (tudi) pri sorodnikih in/ali prijateljih, v turističnih vodnikih, le četrtina pa $\mathrm{v}$ medijih ali turističnih agencijah. Manj pomembni viri informacij so turistični uradi oziroma informacijski centri ter fakultete ( $\mathrm{v}$ primeru študijskih izmenjav).

Anketiranci specifične turistične storitve večinoma rezervirajo prek interneta. V največji meri ga uporabljajo pri rezervaciji letalskih kart, vozovnic za vlak ali avtobus ter zavarovanjih. Pri rezervaciji posameznih izletov in najemu avtomobila pa storitev največkrat rezervirajo oziroma zakupijo osebno na kraju samem (slika 2).

Med anketiranci je bilo najpogosteje uporabljeno prevozno sredstvo za prihod do turističnih destinacij osebni avtomobil, katerega je na potovanjih v zadnjih dveh letih uporabilo $81 \%$ vprašanih; sledili so avtobus (68\%), letalo ( $58 \%)$, vlak ( $42 \%)$, ladja ( $26 \%)$, ter nazadnje kolo in druga prevozna sredstva (obe kategoriji po $4 \%$ ). Obravnavana študentska populacije je na potovanjih najpogosteje bivala v hostlih, sledili so apartmaji in hoteli, manj pogosto pa so prebivali še v najetih hišah, bungalovih ali kampih.

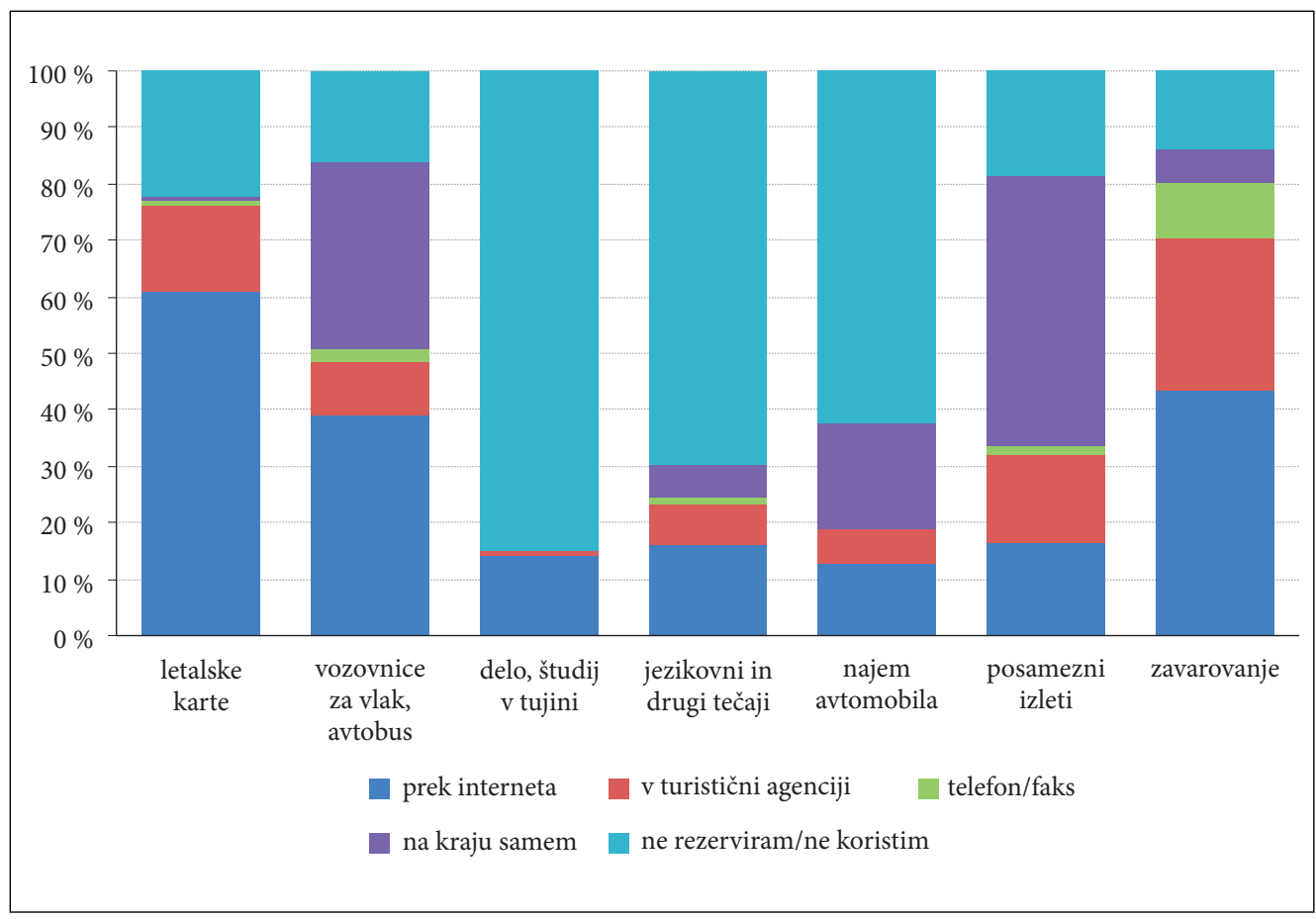

Slika 2: Način rezervacij nastanitev in drugih turističnih storitev/aktivnosti $(N=136)$. 


\subsection{Finančni vidiki potovanja}

Odločilni dejavnik za izbiro potovanja je bila cena, ki jo je kot pomemben oziroma zelo pomemben dejavnik navedlo $94 \%$ anketiranih študentov Univerze na Primorskem. Približno dve tretjini v raziskavo vključenih študentov je kot pomembno ali zelo pomembno ocenilo tudi možnost fleksibilnosti pri spremembah načrta potovanja, možnost rezervacije storitev prek interneta, prometno dostopnost turistične destinacije ter ponudbo storitev v turističnem kraju (mladi in študenti seveda iščejo možnosti sprostitve pri različnih aktivnostih in zabavi). Kvaliteta potovalnih storitev in informacije potovalnih agentov sta sicer še vedno pomembna za večino anketiranih študentov, a bistveno manj v primerjavi z ostalimi dejavniki. Med negativnimi dejavniki ima največji vpliv na izbiro destinacije terorizem (torej nevarnost terorizma in terorističnih groženj na turistični destinaciji), pomembni pa so še kriminal in epidemije, ki imajo pomembno vlogo za nekaj manj kot polovico anketiranih študentov.

Povprečna poraba na potovanju je bila 397,27 evrov, kar glede na povprečno trajanje potovanj pomeni, da anketirani študenti dnevno na potovanju porabijo okoli 55 evrov. Iz strukture porabe sredstev za turistična potovanja, ki jo prikazujemo na sliki 3, je razvidno, da so največji delež denarja porabili za prevoz do destinacije in nazaj (26\%), nastanitev (22\%), hrano in pijačo (18\%) ter druge aktivnosti in zabavo (13\%).

Poznavanje potovalnih oziroma popustniških kartic je med študenti Univerze na Primorskem relativno slabo - na svetovni ravni Mednarodno študentsko izkaznico (International Student Identity Card oziroma ISIC) pozna $92 \%$ mladih med 15. in 29. letom starosti (med anketiranimi študenti le $63 \%$ ), s kartico Hostelling international ali IYHF je seznanjenih $58 \%$ mladih (med anketiranimi študenti le $23 \%$ ), kartico Euro<26 pa $41 \%$ (med anketiranimi študenti $55 \%$ ) (UNWTO 2008, 17). Le pri slednji je med obravnavano študentsko populacijo delež takšnih, ki jo poznajo, višji v primerjavi z mladimi po svetu. Predpostavljamo lahko, da je relativno visoko poznavanje kartice Euro $<26$ pri anketiranih

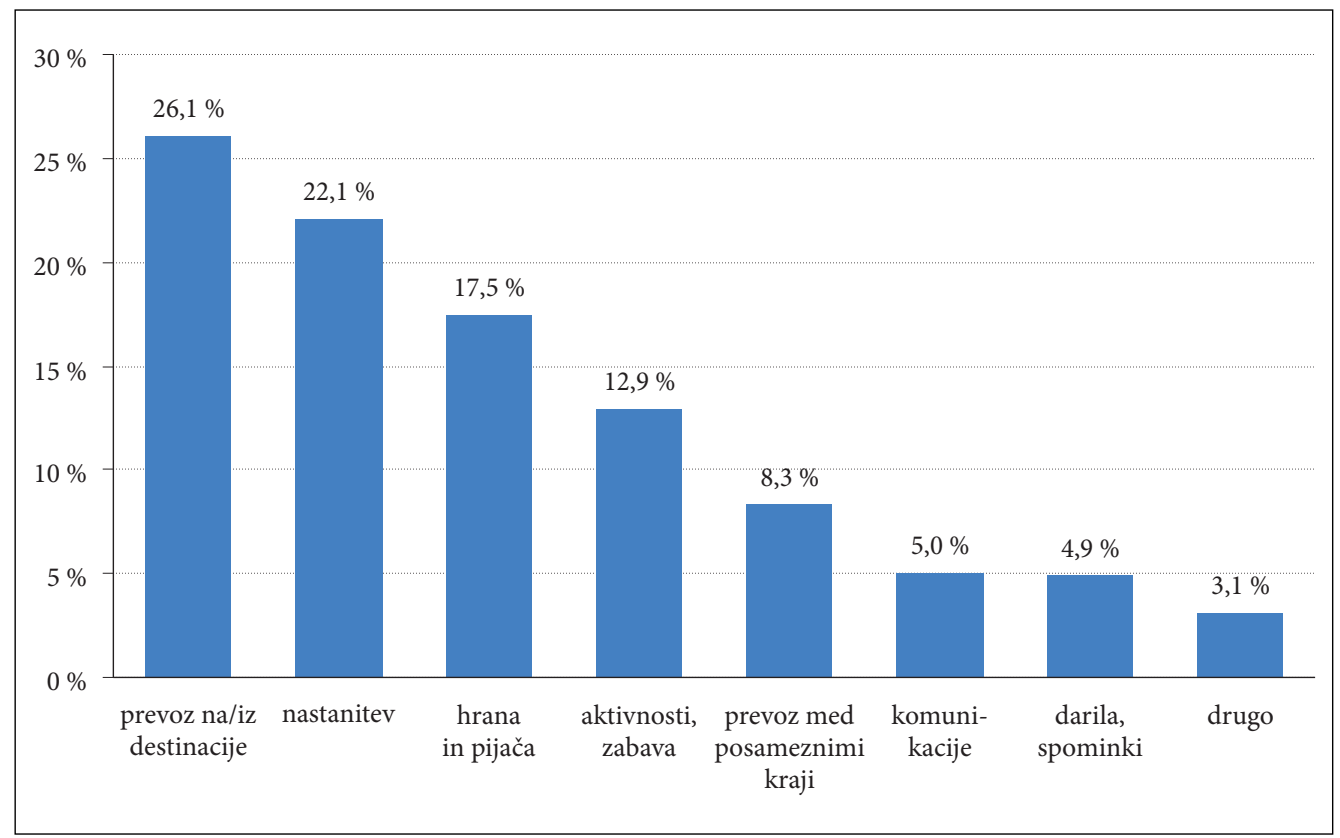

Slika 3: Delež porabe sredstev študentov Univerze na Primorskem na turističnih potovanjih po posameznih postavkah $(N=125)$. 
študentih najverjetneje tudi posledica tega, da jo mladi v Sloveniji uporabljajo za uveljavljanje popustov na medkrajevnih železniških povezavah (prevoz od kraja izobraževanja do kraja stalnega bivališča).

\section{Sklep}

Mladinski turizem predstavlja pomemben segment svetovne turistične dejavnosti. V določenih državah, predvsem tistih v razvoju, že sedaj predstavlja pomemben vir zaslužka, hkrati pa lahko na podlagi trendov zaznamo tudi znaten potencial za nadaljnjo rast.

Pojem mladinskega turizma je sicer težko natančno definirati, saj ob tem »trčimo« na vprašanje definicije "mladih «. Tako se zdi, da mladinskega turizma ni smiselno strogo omejevati le na tisti segment turistične dejavnosti, v katero so kot "potrošniki« vpeti mladi med 15. in 29. letom starosti, saj lastnosti, ki veljajo za "mlade« turiste, lahko veljajo tudi za določene pripadnike (nekoliko starejših) starostnih skupin. Težava je tudi v tem, da v mnogih državah tako (nacionalni) turistični uradi kot statistične agencije sploh ne obravnavajo mladinskega turizma kot posebne kategorije, zato je v mnogo primerih težko priti tudi do najosnovnejših statističnih podatkov.

Na podlagi naše analize ugotavljamo, da med mladimi in študenti prevladuje izrazit individualizem oziroma samostojnost pri organizaciji potovanj, saj se storitev turističnih agencij redkeje poslužujejo. Pomembno vlogo pri tem imajo možnosti, ki jih mladim ponuja (dostopna) moderna tehnologija - še posebej internet, ki je močno poenostavil dostop do potrebnih informacij ter posameznikom omogočil povsem samostojno, individualno organizacijo potovanja. Mladi so tudi sicer turistično visoko mobilni, potujejo več v primerjavi z ostalimi socialnimi skupinami, na potovanjih preživijo več časa ter porabijo več denarja, pri čemer je cena še vedno najpomembnejši faktor pri odločitvi za potovanje.

Mladinski turizem torej predstavlja pomemben del turističnega trga, ki bo v prihodnje še rasel, sploh $\mathrm{z}$ naraščajočim standardom in izobrazbeno strukturo mladih $\mathrm{v}$ državah v razvoju. Hkrati navade mladih pri organizaciji turističnih potovanj (specifične zahteve in samostojnost pri načrtovanju potovanj) predstavljajo izziv tudi turističnim ponudnikom in trgu turističnih storitev nasploh.

\section{Viri in literatura}

Bryman, A. 2012: Social Research Methods. New York.

Commission of the European Communities 2009: EU Youth Report. Medmrežje: http://ec.europa.eu/ youth/documents/youth_report_final.pdf (7.8.2013).

Gosar, A. 1989: Potovanja študentov geografije - primer vrednotenja prostora za rekreativne potrebe specifične socialnogeografske skupine prebivalcev Slovenije/Jugoslavije. Dela 6. Ljubljana.

Gostiša, N. 2000: Družbenogeografske značilnosti turističnih potovanj študentov. Geografski obzornik 47-3. Ljubljana.

Koderman, M. 2008: Nove članice Evropske Unije kot predmet turističnega in geografskega preučevanja med študenti Univerze na Primorskem. Nova Evropa - nova turistična destinacija: zbornik. Portorož.

Mihalič, T. 2008: Turizem: ekonomski vidiki. Ljubljana.

Neuman, W. L. 2006: Social Research Methods: Qualitative and Quantitative Approaches. Boston.

Pehan, V. 2007: Potovalne navade študentov. Diplomsko delo, Fakulteta za družbene vede Univerze v Ljubljani. Ljubljana.

Pogačnik, A. 2008: Prostorsko načrtovanje turizma. Ljubljana.

Richards, G. 2005: ISTC/UNWTO Survey on Student and Youth Tourism among National Tourism Administrations/Organizations. UNWTO: Tourism Market Trends. Medmrežje: http://www.ttr.tirol.at/sites/default/files/upload/UNWTO\%20Student\%20and\%20Youth\%20Travel.pdf (5. 8. 2013). 
Sektor za izobraževanje Univerze na Primorskem: Vpisni podatki za Univerzo na Primorskem za študijako leto 2012/13. Koper, 2013.

SURS - Statistični urad Republike Slovenije 2012a: Turistična potovanja domačega prebivalstva, Slovenija 2011 - končni podatki. Medmrežje: http://www.stat.si/doc/statinf/21-SI-082-1201.pdf (7.8.2013).

SURS - Statistični urad Republike Slovenije 2012b: Mednarodni dan študentov 2012. Medmrežje: http://www.stat.si/novica_prikazi.aspx?id=5136 (19. 8.2013).

SURS - Statistični urad Republike Slovenije 2014a: Demografsko socialno področje. Medmrežje: http://www.stat.si/tema_demografsko_prebivalstvo.asp (1.3.2014).

SURS - Statistični urad Republike Slovenije 2014b: Vpis študentov v višješolsko in visokošolsko izobraževanje, Slovenija, študijsko leto 2013/14 - začasni podatki.

Medmrežje: https://www.stat.si/novica_prikazi.aspx?ID=6104 (1.3.2014).

Swarbrooke, J., Horner, S. 1999: Consumer Behaviour in Tourism. Oxford.

UNWTO - United Nations World Tourism Organization 2001: Thesaurus on tourism and leisure activities: a structured list of descriptors for indexing and retrieving information on tourism and leisure activities. Madrid.

UNWTO - United Nations World Tourism Organization 2008: Youth Travel Matters - Understanding the Global Phenomenon of Youth Travel. Madrid.

WYSE Travel Confederation 2013: Industry Review no. 1: Data, Statistics and Trends. Medmrežje: http://wysetc.org/publications/free-reports/ (15.8.2013).

Zakon o visokem šolstvu. Uradni list Republike Slovenije 67/1993. Ljubljana.

\section{Summary: Youth tourism and travel habits of students - the case of the University of Primorska}

(translated by the authors)

The origins of the contemporary youth tourism are closely connected with development of the tourism industry in the decades after World War II. In this period, young people took part in the changing society and adopted different values and ways of life compared with the pre-war generations (Mihalič 2008, 19). This was also reflected in the way they spend their leisure time as they practiced alternative modes of travel - especially the so called »backpacking « which became widely popular in the 1960's and 1970's and included independent travel on a limited budget. As an alternative to the mass tourist flows, such travel awarded the individual with unique experience of the selected destination and quickly gained in popularity (not just) among the young population.

Today, youth tourism includes several specific niches within the overall market, such as student travel, backpacker tourism, volunteer tourism, language tourism and cultural exchanges (Richards 2005, 101-103). It has become an important segment of the tourism sector as it yearly generates over 160 million international tourist arrivals ( $20 \%$ of total) and accounts 136 billion USD ( $18 \%$ of total). According to the World Tourism Organization (UNWTO 2008, xi), youth tourism experienced a 3 to $5 \%$ annual growth between 2002 and 2007 in the extent of travel and an $8 \%$ growth of revenues per year. Due to the specific characteristics of young population their tourist mobility shows significantly higher average length of stay compared with the "classic « tourists, which consequently results in a higher expenditure. In 2010, the latter accounted a 1,450 USD among the average and 2,600 USD among the young tourists (WYSE ... 2013, 6-8).

The paper mainly focuses on the subject of student tourism - an important category of youth tourism and addresses travel habits of the student population of the University of Primorska (Slovenia). The authors conducted an empirical online survey among 150 students of the six university's faculties. There were altogether 6,606 students enrolled in all study programmes of the university (in first, second and 
third Bologna levels), so the research sample presented $2.27 \%$ of all student population. The sample was balanced according to the principles of quota sampling, therefore the shares of students at each faculty (with regard to the total population) corresponded the shares of respondents from that faculty in the sample (as shown in Table 1). It also reflected the main characteristics of the enrolled students in terms of their study programme ( $81 \%$ of the respondent students were enrolled in the first, bachelor level, $18 \%$ in second, master level, and $1 \%$ in the third, doctoral level).

Analysis of the results shows high mobility of the respondent student population. Most popular destinations for students are similar to those, visited by other residents of Slovenia (SURS 2012a, 1). They include tourist towns and areas in Slovenia (especially in the Gorenjska, Obalno-Kraška, Goriška and Pomurska statistical region - shown also in Figure 1) and in the neighboring countries of Croatia, Italy and Austria, which received most of the visits. Other European (Czech Republic, France, Germany, Spain and Greece) and non-European (Egypt, Thailand, United States of America, Morocco, Malaysia, Honduras and Guatemala) countries followed, the latter however showed significantly lower shares of student visits.

Another aspect of research focused on the frequency and length of travel. Students usually participate in tourist trips between May and September - a period closely connected with the end of their study obligations. The majority of the student trips lasted up to 10 days, while the average was 7.17 days. Among the motives for the travel students frequently exposed the desire for rest and entertainment (56\%), followed by the desire to discover foreign places and cultures (31\%) and visiting friends and relatives (7\%). Two thirds of student respondents have organized their trips individually; others used services of travel agencies. Students most often turned to travel agencies for the reservation of plane ticket or accommodation, only $14 \%$ of them travelled on a package tour, entirely organized by travel agencies. 